\title{
REPRESENTAÇÕES RUPESTRES DE ADORNOS DE CABEÇA NOS ANTROPOMORFOS NA ÁREA ARQUEOLÓGICA DO SERIDÓ - RN ${ }^{1}$
}

\author{
Daniela Cisneiros ${ }^{2}$ \\ danielacisneiros@yahoo.com.br \\ Nathalia Nogueira ${ }^{3}$ \\ nathalia.c.nogueira@gmail.com
}

\section{RESUMO}

A pesquisa teve como objetivo identificar, segregar e correlacionar a partir das tipologias apresentadas as cenas gráficas que continham a representação do adorno de cabeça nos antropomorfos nos sítios inseridos na Área Arqueológica do Seridó. Realizou-se um estudo que ressalta os aspectos morfológicos constituintes da cena com o propósito de identificar padrões de apresentação gráfica. Para atingir as metas propostas, foi utilizada a abordagem analítica das dimensões do fenômeno gráfico: temática, cenográfica e técnica, visando obter dados sobre a estrutura gráfica dos componentes cênicos e suas correlações espaciais. Foram analisados 9 sítios e 30 cenas que resultaram na identificação de 17 tipos de adornos de cabeça vinculados a 4 temáticas diferentes: hermética, violência, sexo e caça.

Palavras-chave: Pintura Rupestre, Adornos, Seridó.

\footnotetext{
${ }^{1}$ Resumo de Dissertação de Mestrado apresentada ao Programa de Pós-graduação em Arqueologia e Preservação Patrimonial, UFPE, defendida em outubro de 2016.

${ }^{2}$ Departamento de Arqueologia da UFPE.

${ }^{3}$ Discente do Programa de Pós-graduação em Arqueologia da UFPE.
} 


\begin{abstract}
The research aimed to identify, segregate and correlate through the typologies presented to the graphic scenes that contained the representation of the head adornment in the anthropomorphs in the archaeological sites inserted in the Area Archaeological of Seridó. A study was carried out highlighting the morphological aspects constituting the scene with the purpose of identifying patterns of graphic. To reach the proposed goals the analytical approach of the dimensions of the graphic phenomenon was used: thematic, scenographic and technical, aiming to obtain data about the graphic structure of the scenic components and their spatial correlations. In this way 9 sites and 30 scenes resulting with the identification of 17 types of head adornments related to 4 different themes: hermetic, violence, sex and huntingKeywords: Cave Painting, Cultural Attribute and Anthropomorphic
\end{abstract}

Keywords: Cave Painting, Cultural Attribute and Anthropomorphic

\title{
ANTECEDENTES
}

Ao longo do século XX, as pesquisas sobre as manifestações gráficas tiveram um aprimoramento dentro do enfoque arqueológico: ultrapassaram a barreira interpretativa da arte pela arte e receberam uma nova abordagem, que traz uma perspectiva de que as pinturas e as gravuras são consideradas registros gráficos e, assim, fonte de dados para a pesquisa arqueológica.

Com isso, pesquisas relacionadas aos registros gráficos puderam incorporar novas abordagens teóricas e metodológicas, corroborando com a compreensão sobre as capacidades e habilidades cognitivas do homem pré-histórico.

Para compreender e apreender o mundo real ou imaginário e interagir com os demais, o Homem utiliza-se de recursos da linguagem (verbal e não verbal), como a voz, o gesto e a representação gráfica, entre outros, dependendo dos recursos materiais conhecidos e disponíveis. Desse modo, é de suma importância a reflexão sobre as diferentes maneiras 
pelas quais o homem pré-histórico pôde se expressar, compreender e se fazer entender em relação a outros indivíduos, dentro e fora do seu grupo.

Esta pesquisa parte da ideia de que as manifestações gráficas são códigos comunicativos que, ao serem impressos nos paredões rochosos, atribuíam significados articulados social e culturalmente entre seus participantes.

Dentro dessa perspectiva, Pessis (1992) elaborou um módulo investigativo a partir de parâmetros designado dimensões do fenômeno gráfico rupestre. A partir destes, abrem-se possibilidades de investigação do fenômeno gráfico em três componentes analíticos: temática, técnica e cenográfica. Esses componentes analíticos buscam a compreensão do universo simbólico através das informações advindas das preferências gráficas e dos possíveis modos como esses elementos estão relacionados, espacialmente no suporte rochoso. Esse aspecto permite ao arqueólogo perceber parte dos componentes do sistema cultural que foi transmitido a partir da percepção do autor sobre o mundo que o envolvia, através de uma análise sistemática da imagem dentro do conjunto gráfico.

\section{O CORPO COMO SUPORTE DE ATRIBUTOS CULTURAIS}

De acordo com os estudos etnográficos, o corpo humano é retratado como ferramenta social de discurso, contendo diversos elementos conceituais e de configuração estética que demonstram a elaboração e fabricação da imagem corpórea de cada grupo. Vidal e Müller (1986) ressaltam ainda que essa apresentação visual do corpo exprime a concepção tribal da pessoa humana, a categorização social e outras mensagens referentes à ordem social. 
Com isso, o corpo pode ser atribuído a um sistema de comunicação visual com estruturas simbólicas para os diversos momentos sociais e religiosos, contendo relações com os outros meios comunicacionais, tanto os verbais quanto os não verbais. Segundo Seeger, Matta e Castro (1979), o corpo afirmado ou negado, pintado ou perfurado, resguardado ou devorado, tende sempre a ocupar uma posição central na visão que as sociedades têm da natureza do ser humano. Com isso, a produção física de indivíduos se insere em um contexto voltado para a produção social da pessoa.

O corpo também pode ser interpretado como um sistema de significados e valores que comunica a identidade pessoal e social do indivíduo. Essa comunicação é representada pela sua fabricação e exibição, perante os atributos relacionados ao corpo e sua cultura (Ribeiro, 1987).

Para tanto, a apresentação da identidade pessoal e coletiva atrelada ao indivíduo e aos grupos pode ser retratada através dos campos de criatividade humana dos atributos culturais, compreendendo objetos atribuídos ao corpo com significação própria da sua cultura e utilização. Esses atributos culturais podem estar relacionados às vestimentas, aos adornos, entre outros, produzindo assim uma manifestação estética e de ornamentação corporal associadas ao aspecto artístico e simbólico dos grupos culturais.

A caracterização do indivíduo, tanto no aspecto da vestimenta quanto dos ornamentos corporais, é de grande importância no que concerne à identidade pessoal, grupal e a seu sentimento de posse e pertença. Assim, viver com o traje relativo ao seu grupo assegura simultaneamente a sensação de existir enquanto elemento individual de um grupo em que se desempenha um papel em nível pessoal e uma sensação de oposição relativamente aos outros grupos. Desse modo, a decoração vestimentar assegura o reconhecimento e orienta o comportamento ulterior, não se desassociando das atitudes, dos ornamentos e da 
linguagem, que completam esse reconhecimento e organizam o comportamento de relação (LEROI-GOURHAN, 1965). (Figura 1)

Contudo, ao estudar a apresentação da postura vestimentar perante sua importância na construção do indivíduo, não há como dissociá-la da utilização dos adornos, pois há uma complementação mútua entre significados e representatividades.

Os adornos são compreendidos como elementos materiais inseridos ao corpo para assegurar ao indivíduo, assim como a vestimenta, uma identidade pessoal e grupal. Há diferentes tipos de adornos. Entre eles podem ser observados os arranjos corporais de uma forma mais geral, como pentes, pulseiras, braçadeiras, tornozeleiras, cinturões, faixas, entre outros. Os arranjos de decoro estão relacionados a vestimentas, em decorrência de sua utilização e representatividade no corpo.

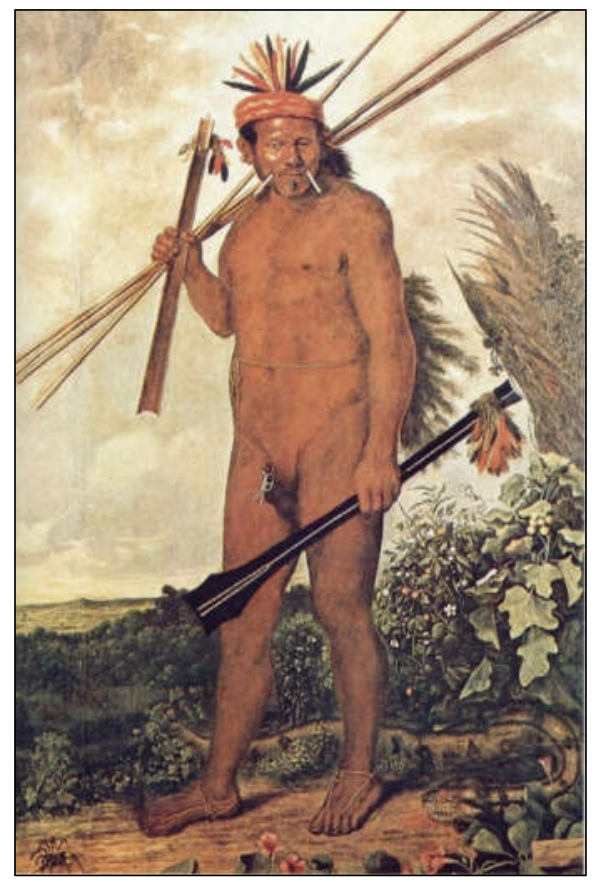

Figura 1: Índio Tapuia, com adornos na cabeça, na orelha, na face, no corpo e nos pés. Pintura de Eckhout, A. Fonte: Santos Junior, 2008. 
De acordo com Leroi-Gourhan (1965), o adorno tem, sobretudo, um valor étnico, pois a presença em um dado grupo começa por ser sancionada em função da decoração. Assim, o corpo é um suporte comunicacional, onde são vinculados atributos que carregam um valor étnico e simbólico pertencente a grupos distintos, diferenciando-os entre si, intra e extragrupo, tendo em vista que os atributos estão carregados de sinais que permitem tais distinções.

Efetivamente, essa identificação é o que determina as diferentes relações com o homem, como o encontro do dominante com o dominado, masculino e feminino, desencadeando relações afetivas conforme as normas das relações intraétnicas (LEROI-GOURHAN, 1965).

Além da atuação dos adornos perante o homem e a sociedade, o cabelo também se comporta como um elemento importante na construção corporal, considerando sua utilização para fins higiênicos, estéticos e adornais ao longo da história do homem, como pode ser visto na cultura egípcia (Figura 2).

Para Leach (1978), a arte do penteado pode ser considerada como objeto de elaboração ritualista; nos estudos sobre as sociedades, é notável a presença ou ausência do cabelo da cabeça permeadas de sentidos e linguagem e o sentimento de identidade e pertença para os grupos.

Em decorrência da impossibilidade, até o presente momento, de distinção de dados sobre a constituição dos adornos de cabeça e penteados apresentados nas pinturas rupestres, todos os componentes atribuídos à cabeça nas manifestações gráficas foram classificados, nesta pesquisa, como adornos. 


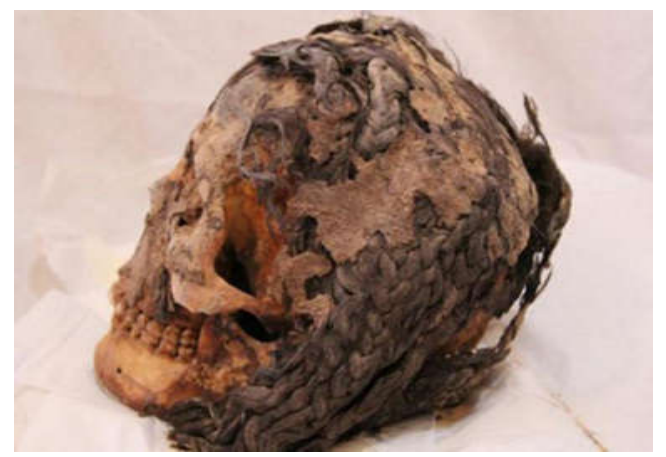

A

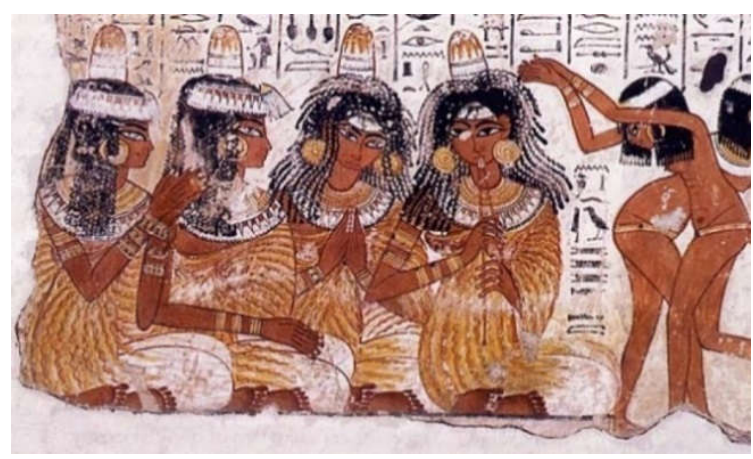

B

Figura 1: (A) Esqueletos evidenciados por arqueólogos no Egito com mais de 3.300 anos BP, com penteados elaborados. (B) Mural egípcio apresentando tranças e elaborados penteados. Fonte: Livescience, September 17, 2014.

\section{ADORNOS DE CABEÇA NOS GRAFISMOS RUPESTRES}

As representações gráficas rupestres que apresentam um atributo cultural em sua composição cenográfica, seja uma arma, uma vestimenta, um objeto de mão ou um adorno de cabeça, constituem-se, em sua grande maioria, como parte de um processo cultural pertencente a grupos pré-históricos que não existem mais, assim como seus significados. Representam o aspecto da transposição de elementos do cotidiano e do imaginário para os paredões rochosos e a demonstração da utilização do corpo como suporte de acumulação de símbolos.

Esse tipo de representatividade rupestre pode ser encontrado em diferentes lugares do mundo. Nele, primeiramente pode-se observar a necessidade do ser humano no geral de agregar ao corpo atributos de significados próprios e específicos vinculados à cultura a que pertence, para posteriormente haver a exteriorização para as pinturas rupestres. Muitas vezes esses atributos culturais importam mais em sua representação do que a identidade sexual apresentada manifesta através da representação dos órgãos sexuais (Figuras 3 e 4). 

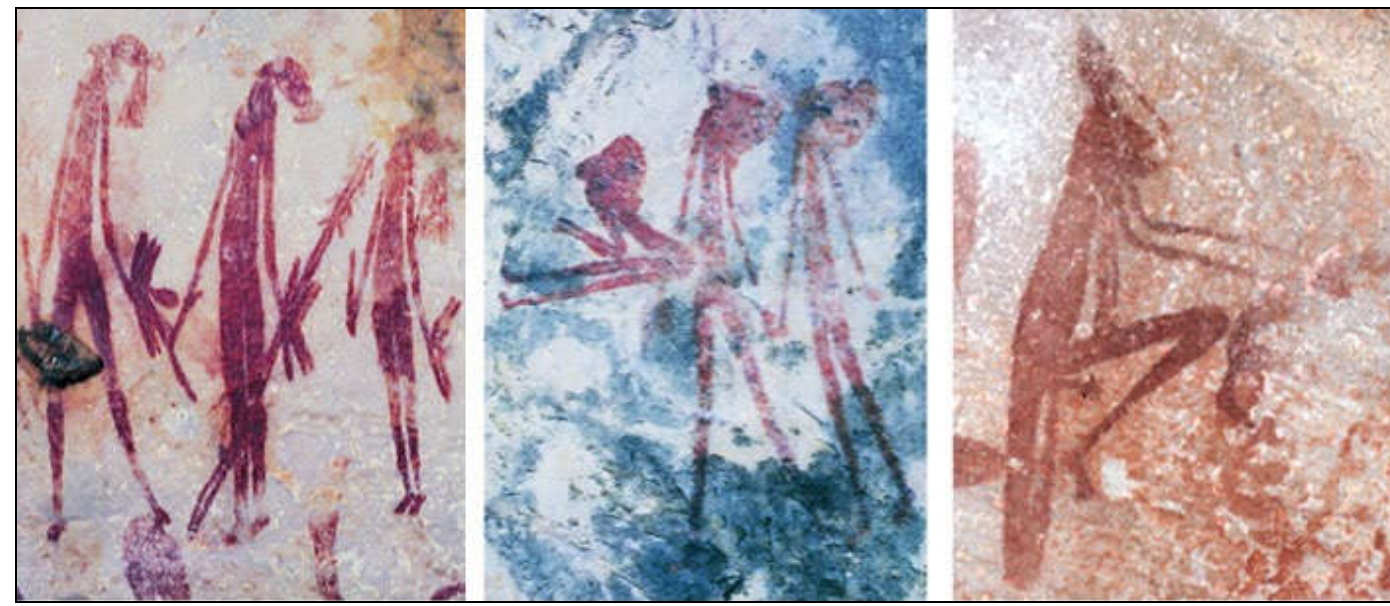

Figura 3: Pintura rupestre de antropomorfos com adornos de cabeça - região de Kimberley (Gwion). Fonte: Kimberley Foundation Australia, 2012.

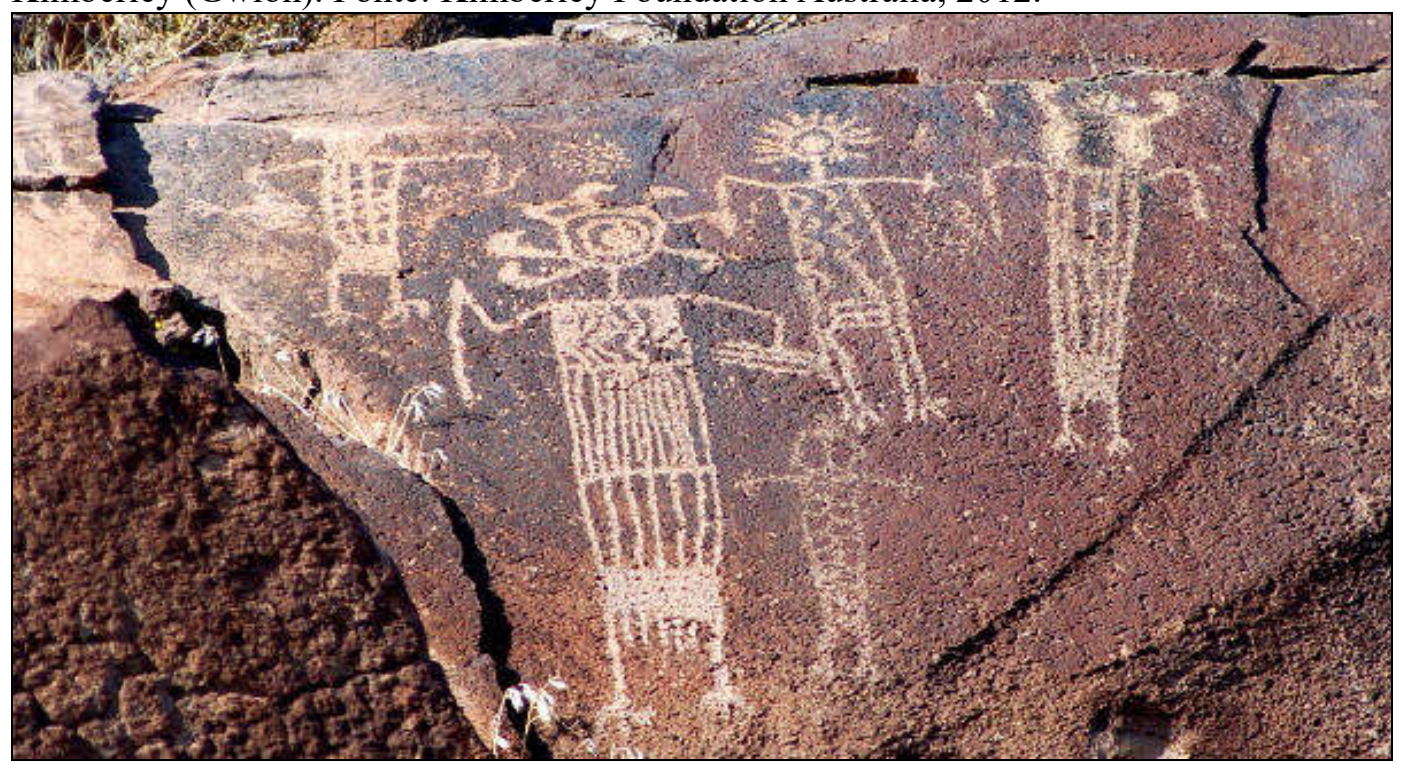

Figura 4: Gravuras rupestres de antropomorfos com adornos na cabeça - região do Coso, Califórnia. Fonte: Garfinkel. A. P., 2007.

No Brasil, figuras formando cenas e com adornos apresentam-se concentradas nas regiões com presença de pinturas rupestres da Tradição Nordeste, como na Área Arqueológica da 
Serra da Capivara e no Seridó (Figura 5). Nas demais áreas, a utilização de adornos nos antropomorfos ocorre em geral de forma isolada; os indivíduos não são representados interagindo entre si.

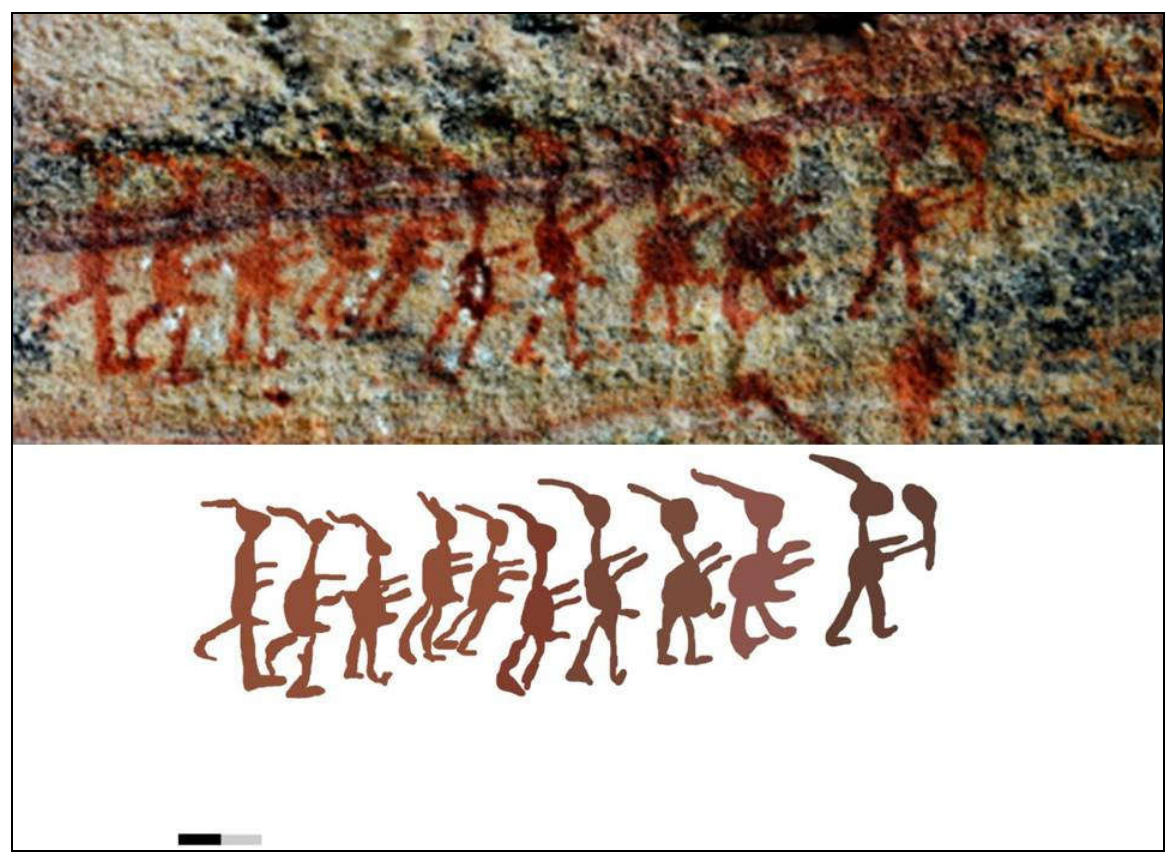

Figura 5: Pinturas rupestres com adornos na cabeça - Serra da Capivara. Fonte: Araújo, 2010.

$\mathrm{Na}$ análise das imagens pictóricas rupestres, foi possível observar que os adornos de cabeça atribuídos aos antropomorfos estudados estão localizados na parte occipício da cabeça, com distintas formas. 


\section{GRAFISMOS RUPESTRES NA ÁREA ARQUEOLÓGICA DO SERIDÓ}

A Área Arqueológica do Seridó é composta por uma grande concentração de sítios com pinturas e gravuras rupestres. Os vestígios da cultura material deixados por esses grupos ajudam, atualmente, na construção dos estudos sobre a pré-história do Nordeste brasileiro.

A partir de pesquisas sobre os registros rupestres da região, foram observadas semelhanças entre as pinturas encontradas no sudeste do Piauí e as do Seridó (MARTIN, 1989). Verificou-se que as pinturas rupestres de ambas as localidades continham estruturas morfológicas e apresentação gráfica semelhantes, sendo caracterizadas como Tradição Nordeste. Contudo, esses grafismos apresentavam algumas variações que as diferenciavam de outros locais, tornando-as características das pinturas encontradas na região; em decorrência dessas modificações pictóricas, as pinturas que tinham tais variantes foram denominadas de Subtradição Seridó.

Segundo Martin (1989), as subtradições são diferenciáveis pelo critério de unidades regionais e pelo tratamento específico, de acordo com a apresentação gráfica típica da Tradição. A Subtradição Seridó, por exemplo, tem as características principais da Tradição Nordeste, como, por exemplo, a presença majoritária de grafismos reconhecíveis, dispostas tanto isoladas quanto formando cenas. Além de suas características próprias, como a dominância de antropomorfos em relação às demais representações, há também a chamada cabeça de castanha-de-caju, a tendência de utilização de componentes que permitem o reconhecimento de determinadas espécies de animais e as características próprias adquiridas pelos indivíduos através da adaptação do meio envolvente, que a definiram como uma subtradição (MARTIN, 2008). 
A partir de uma densa análise nas particularidades dos painéis pictóricos, foram identificados diferentes estilos, que, hipoteticamente, constituem uma evolução cronológica demonstrada através da técnica, da temática e da cenografia aplicada aos diversos grupos que habitaram a região nas apresentações gráficas.

Esses estilos são denominados como Serra da Capivara II, Carnaúba e Cerro Corá. O estilo Serra da Capivara II foi definido para representar o primeiro momento dessa manifestação, tendo em vista as semelhanças com as pinturas encontradas no Parque Nacional Serra da Capivara, situado no sudeste do Piauí. O estilo Carnaúba representa a segunda fase da atividade pictórica, tendo como traço gráfico a representação da "cabeçade-caju" e as "pirogas". O estilo Cerro Corá se distingue dos demais estilos da região, pois tem traços geométricos, assemelhando-se com a Tradição Agreste (MARTIN, 2003).

Aceitando-se que cada grupo cultural, e cada segmento de sociedade, têm procedimentos próprios para se apresentar a observação de outrem, e que cada membro do grupo utiliza esses comportamentos por ocasião de qualquer interação social, pode-se pensar que tais procedimentos estarão presentes nas representações gráficas de um grupo cultural. Em consequência, a análise da obra gráfica do homem pré-histórico, procurando identificar os padrões de apresentação das imagens rupestres, constitui um modo de ascender a sua cultura (PESSIS, 1989).

Deste modo, esta pesquisa buscou as correlações entre a tipologia dos adornos de cabeça e as cenas representadas nas apresentações gráficas.

Levando em consideração a análise gráfica dos sítios pesquisados, partiu-se da hipótese de que existem correlações na estrutura gráfica entre os adornos de cabeça e as cenas 
representadas, demonstrando com isso uma interação cultural entre os indivíduos realizadores de tais representações.

Para tanto, o objetivo geral desta pesquisa consistiu na identificação de recorrências dos tipos morfológicos dos adornos de cabeça em relação a determinadas cenas nas pinturas rupestres na bacia hidrográfica do Rio Carnaúba.

\section{METODOLOGIA DA PESQUISA}

Em atendimentos à problemática e a hipóteses propostas na pesquisa, foi introduzido o embasamento metodológico proposto por Pessis (1992) sobre os estudos dos registros rupestres, no que concerne a dimensão do fenômeno gráfico, assim como a análise do sítio arqueológico visto como um espaço para manifestação gráfica.

As dimensões do fenômeno gráfico podem ser apresentadas da seguinte forma:

1. Temática - refere-se aos elementos cognitivos essenciais para o reconhecimento dos grafismos estabelecidos no conjunto gráfico.

2. Cenográfica - refere-se ao agenciamento e isolamento das unidades no espaço gráfico perante as suas dimensões e disposições espaciais e geomorfológicas, sendo estabelecidos a partir de análises morfométricas.

3. Técnica - refere-se aos procedimentos técnicos de execução do grafismo rupestre exposto no paredão rochoso.

As variáveis trabalhadas em cada dimensão podem ser sintetizadas nos três quadros abaixo. Essas variáveis foram trabalhadas de forma isolada e posteriormente analisadas em conjunto. 


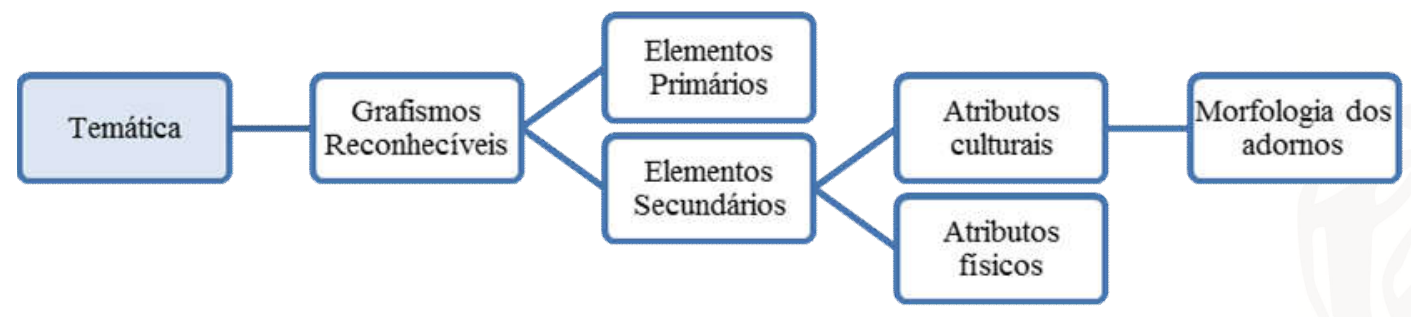

Quadro 1: Variáveis da Temática

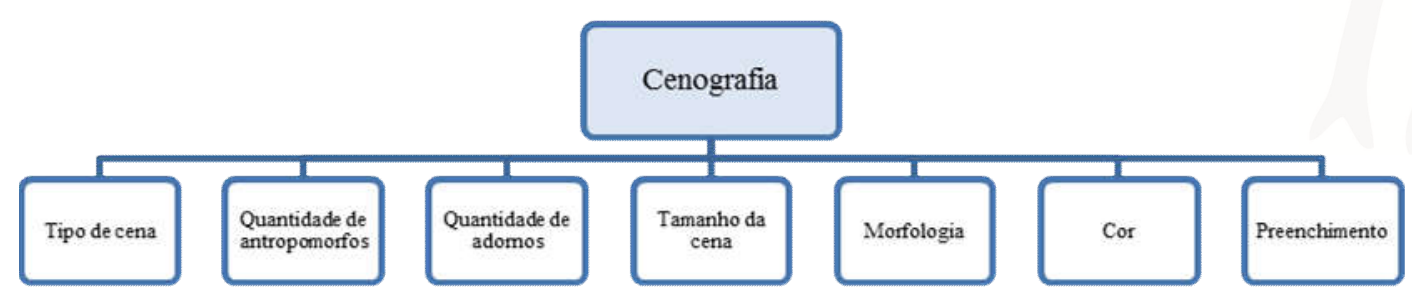

Quadro 2: Variáveis da Cenografia

Quadro 3: Variáveis da Técnica.

\section{ANÁLISE E DISCUSSÃO DOS RESULTADOS}

Foram analisados 48 sítios na bacia hidrográfica do Rio Carnaúba. Destes, 9 apresentavam cenas que continham antropomorfos com adornos na cabeça, foram eles: Casa Santa, Furna da Desilusão, Furna do Borrachinha, Furna do Messias, Serrote das 
Areias, Xique-Xique I, Xique-Xique II, Xique-Xique IV e Sítio do Hélder. É importante mencionar que foram identificados outros antropomorfos isolados que apresentavam adornos, mas que não integravam cenas.

Com a identificação dos sítios selecionados para a pesquisa, foi necessária a identificação e caracterização das composições cenográficas que continham as representações antropomórficas com adornos de cabeça, para, posteriormente, serem analisados os tipos de adornos de cabeça apresentados nas distintas cenas.

A análise dos sítios privilegiou as cenas com a presença de antropomorfos e com adornos de cabeça. Dessa maneira, do total de 88 cenas identificadas nos sítios pesquisados, em apenas 30 aparecem antropomorfos com adornos na cabeça.

Para a construção da pesquisa, foi realizada, inicialmente, a identificação dos grafísmos reconhecíveis presentes nos paredões rochosos. Esse reconhecimento se deu primeiro através dos elementos primários constituintes das figuras humanas, como: cabeça, tronco e membros (superiores e inferiores).

Verificou-se que a totalização dos antropomorfos pintados tem forte correspondência com a presença dos elementos primários de reconhecimento em todas as figuras da cena. A ausência de parte desses elementos faz-se notar por problemas de conservação dos grafismos e/ou do suporte, e não por intencionalidade de ocultar esses elementos.

Em seguida, foram identificados os elementos secundários, que podem ser retratados como atributos culturais (adornos, armas e objetos de mão), e partes físicas do corpo humano, mas que não participam dos elementos de reconhecimento imediato (falo, vulva, pés, mãos). Esse processo resultou nos seguintes dados: dos 89 antropomorfos 
distribuídos em 30 cenas estudadas, 64 têm adornos de cabeça, 8 portam armas, 7 portam objetos de mão. Indicando com isso que $56,96 \%$ dos antropomorfos que compõem as cenas analisadas estão com adornos de cabeça. Dos antropomorfos com adornos, 4 têm objetos de mão, 6 portam armas.

$\mathrm{Na}$ análise dos elementos secundários (atributos físicos), observa-se a identificação de falo em 4 antropomorfos e de vulva apenas em 1. Dos antropomorfos que apresentam falo, 1 tem adornos e o que apresenta a vulva não possui adorno. Como dito anteriormente, parece, através das cenas analisadas, que a representação dos órgãos é de menor interesse na representação da figura humana que a representação dos adornos de cabeça.

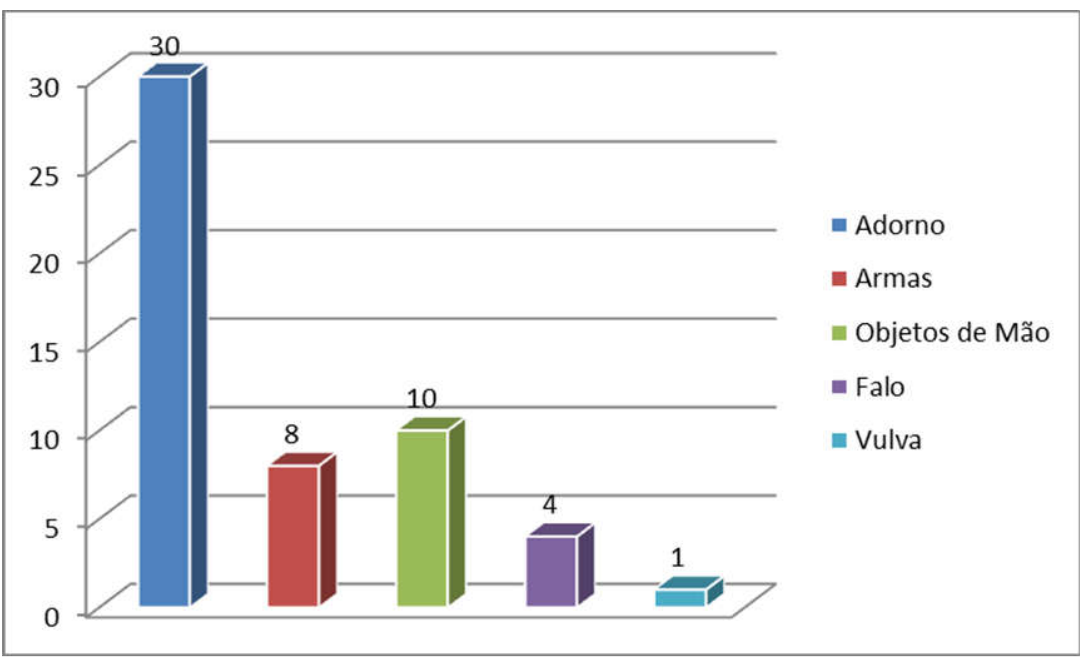

Gráfico 1:

Distribuição dos elementos secundários, identificação dos atributos culturais e físicos nas cenas estudadas.

No que se refere aos adornos de cabeça, foi constatada a presença de diferentes formas atribuídas aos antropomorfos. Desse modo, foi essencial para a pesquisa a identificação e segregação das diferentes formas exibidas por tipologias. Nos 64 adornos analisados, houve a identificação de 17 tipos diferentes (Quadro 4). 


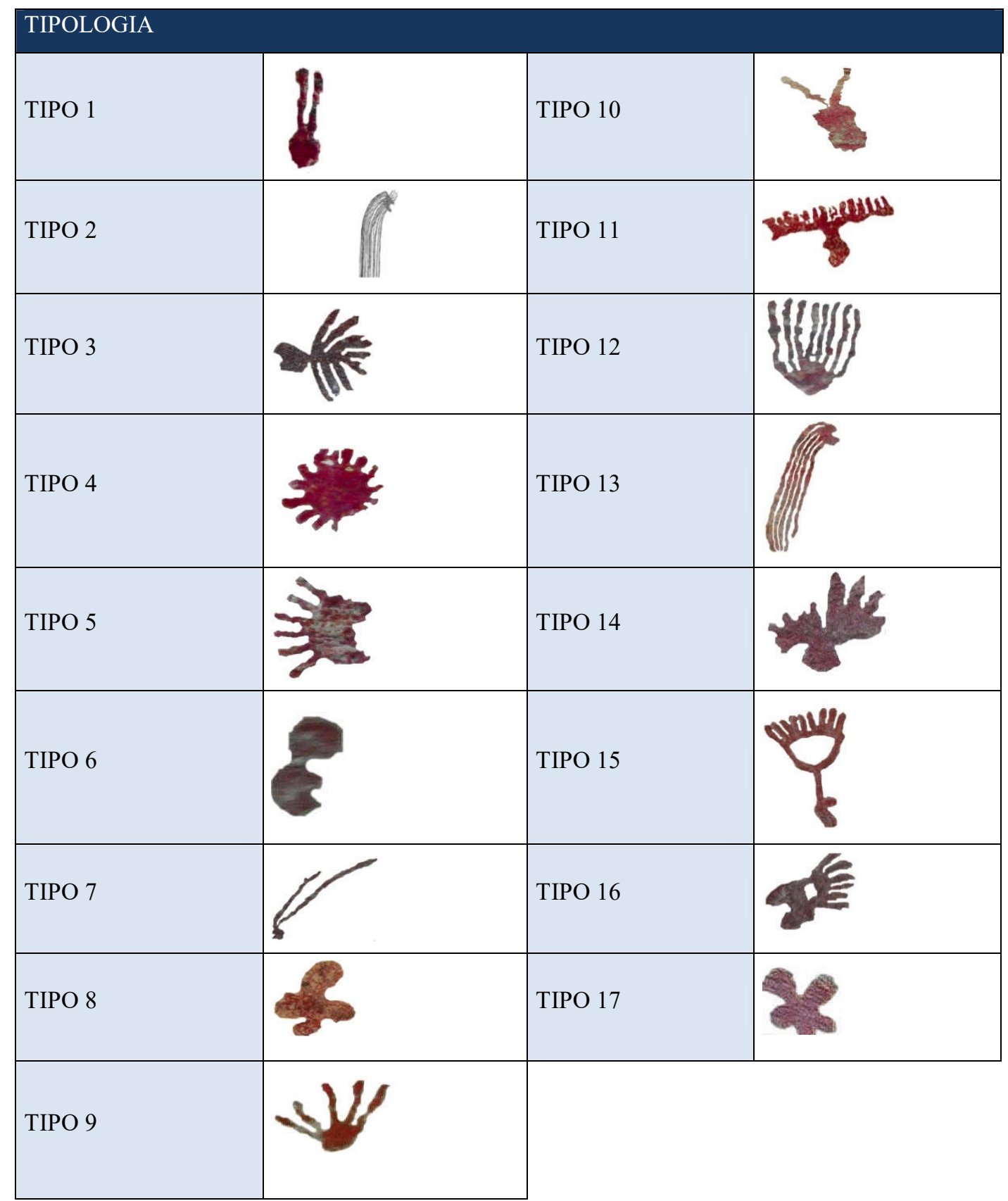

Quadro 4: Tipologias dos adornos de cabeça. 
Após o reconhecimento mediante a apresentação dos antropomorfos e os atributos que os acompanham, foi percebida em algumas composições a presença de zoomorfos e pirogas, tornando-se necessária sua identificação e mensuração perante os sítios para conclusão do reconhecimento dos elementos que constituem as composições gráficas estudadas.

Quanto ao tipo de cena, temos uma constante de reconhecimento: caça, sexo, violência e herméticas ${ }^{4}$. Apesar do número baixo de cenas, a constante reconhecimento se mantém, em que, das 30 cenas com adornos na cabeça, 25 são herméticas, 1 é de violência, 2 são de sexo e 2 são de caça (Quadro 5).

Quanto à variável tamanho, em relação às cenas, foi mensurada através das medições dos pontos mais distais existentes na cena $(\mathrm{C} \times \mathrm{L})$. Dessa forma, foi identificado que suas medições apresentam em relação ao menor $6,4 \mathrm{~cm}$ x $5,2 \mathrm{~cm}$ e ao maior $32,6 \mathrm{~cm} \times 8,9 \mathrm{~cm}$, não apresentando uma constante em suas dimensões e demonstrando assim uma variedade sobre tal mensuração.

Diferentemente, a variável cor se apresenta de forma constante nas cenas estudadas, com exceção da cena 1 do sítio Furna da Desilusão, que se manifesta na cor preta, tornando-se única entre as cenas com adornos de cabeça entre os sítios pesquisados.

\footnotetext{
${ }^{4}$ Chamamos de cenas herméticas aquelas representações rupestres que apresentam uma coerência interna com uma lógica em sua constituição, entretanto sua significação enquanto ato cenográfico é limitada ao grupo cultural pelo qual foram realizadas. De acordo com Pessis (2003), para compreender o sentido é necessária informação suplementar de outros registros complementares, como o verbal, o gestual e os meios de transmissão de conhecimento próprios da tradição oral.
} 
A respeito da variável preenchimento, notou-se que em relação aos antropomorfos ela se apresenta nas 29 das 30 cenas, com exceção da cena 5 do sítio Xique-Xique I. Acerca da variável relacionada aos tipos de adornos e as cenas estudadas, não foram identificadas possíveis associações entre a existência ou não de preenchimento nos antropomorfos e o tipo de adorno de cabeça utilizado.

\begin{tabular}{|c|c|c|c|c|c|c|}
\hline SÍTIOS & CENAS HE & IETICAS NO & SÍTIOS & & & \\
\hline Casa Santa & HWtetek & & 4) & 象选 & su & \\
\hline $\begin{array}{l}\text { Furna da } \\
\text { Desilusão }\end{array}$ & at & & & & & \\
\hline $\begin{array}{l}\text { Furna do } \\
\text { Borrachinha }\end{array}$ & h' & & & & & \\
\hline $\begin{array}{ll}\text { Furna do } \\
\text { Messias }\end{array}$ & $x+2 x x^{3}$ & y & 美美文入文 & का & 1 & \& \\
\hline $\begin{array}{l}\text { Serrote das } \\
\text { Areias }\end{array}$ & $4 \sqrt{x}$ & & & & & \\
\hline $\begin{array}{ll}\text { Sítio do } \\
\text { Hélder }\end{array}$ & (5) & & & & & \\
\hline $\begin{array}{l}\text { Xique- } \\
\text { Xique I }\end{array}$ & $x+x+x+x$ & 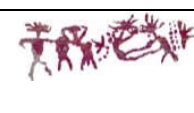 & & & & \\
\hline $\begin{array}{l}\text { Xique- } \\
\text { Xique II }\end{array}$ & & 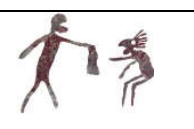 & (r) & & & \\
\hline $\begin{array}{l}\text { Xique- } \\
\text { Xique IV }\end{array}$ & है & 被? & & & & \\
\hline
\end{tabular}

Quadro 5: Cenas herméticas que apresentam adornos de cabeça. 
$\mathrm{Na}$ análise foi identificado que, na construção gráfica das 30 cenas, seus elementos constituintes foram projetados, na maioria dos casos, de forma simétrica: 27 cenas apresentam componentes simétricos; e 3, assimétricos. Percebe-se, com isso, que os autores gráficos deram preferência a uma construção em relação aos elementos constituintes da cena, um equilíbrio sobre a proporção total exibida.

A partir da identificação das cenas, foi constatado que esse tipo de expressão gráfica é recorrente em todos os sítios arqueológicos estudados e provavelmente carregam conteúdo simbólico e de comunicação pertencentes aos grupos que compartilhavam características culturais.

Nesse sentido, após a segregação das composições cenográficas, foi possível perceber que as cenas classificadas como herméticas apresentam características semelhantes: o tipo de adorno de cabeça, por exemplo, está relacionado a vários tipos de agenciamento cenográfico.

Dessa maneira, para a avaliação sobre as similaridades e diferenças foi levado em consideração o tipo de adorno de cabeça agregado à cena, a fim de obter e afinar a classificação e com isso serem alcançados dados sobre a proposta da pesquisa (Quadro 6).

\begin{tabular}{|l|l|l|l|l|l|}
\hline Casa Santa & $\begin{array}{l}\text { Xique- } \\
\text { Xique IV }\end{array}$ & $\begin{array}{l}\text { Furna da } \\
\text { Desilusão }\end{array}$ & $\begin{array}{l}\text { Furna do } \\
\text { Messias }\end{array}$ & $\begin{array}{l}\text { Xique- } \\
\text { Xique II }\end{array}$ & $\begin{array}{l}\text { Serrote das } \\
\text { Areias }\end{array}$ \\
\hline
\end{tabular}

Quadro 6: Cenas herméticas similares com adornos de cabeça tipo 2. 
As composições cenográficas que apresentam o adorno de cabeça tipo 2 estão vinculadas a agenciamentos semelhantes, como nas cenas dos sítios Casa Santa e Xique-Xique IV, que exibem composições com os antropomorfos em posição frente a frente, com a presença de um antropomorfo menor entre ambos. Essa composição cenográfica também é uma cena emblemática da subtradição Seridó.

As cenas dos sítios Furna da Desilusão, Furna do Messias, Xique-Xique II e Serrote das Areias apresentam arranjo semelhante, tendo em vista a interação que ocorre em duplas, apesar de a disposição dos antropomorfos apresentarem diferenças, e, em ambas as composições, é possível identificar a presença de uma espécie de vestimenta no antropomorfo.

As cenas nos sítios Casa Santa, Furna do Messias e Xique-Xique IV apresentam algumas características semelhantes, como: os adornos de cabeça que têm a mesma morfologia, sendo classificados como tipo 5; os antropomorfos que estão caracterizados com a mesma morfologia de vestimenta; e os antropomorfos que estão interagindo entre si (Quadro 7).

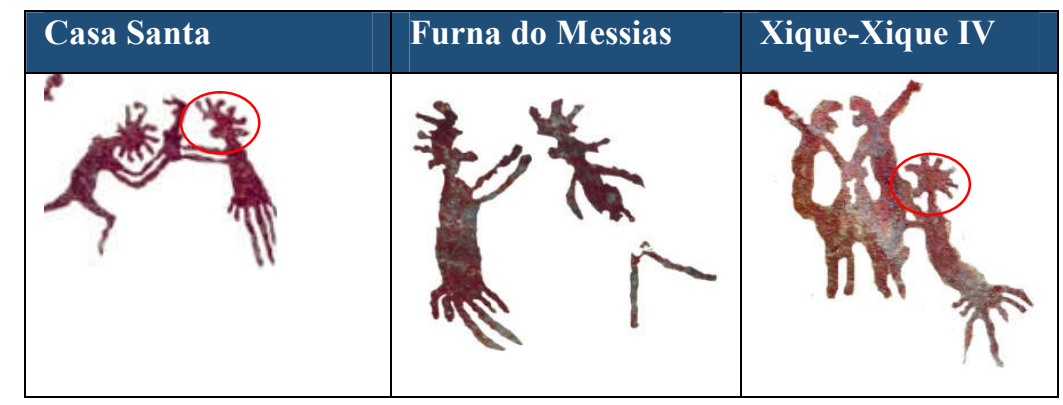

Quadro 7: Cenas herméticas similares com adornos de cabeça tipo 5. 
As composições dos sítios Furna do Messias e Xique-Xique IV apresentam algumas características semelhantes, como: tipo do adorno 17 nos antropomorfos em cena; e antropomorfos agenciados de forma semelhante, lado a lado, com os membros inferiores em posição aberta (Quadro 8).

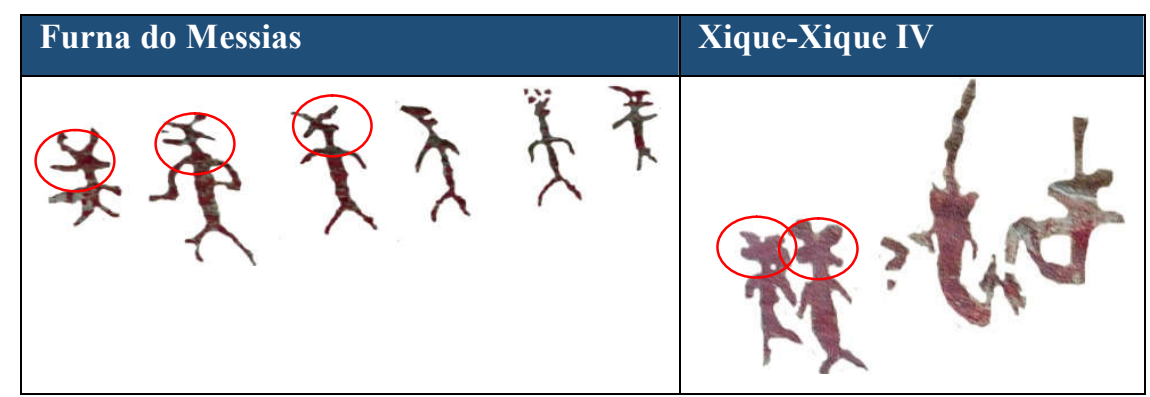

Quadro 8: Cenas herméticas similares com adornos de cabeça tipo 17.

As composições dos sítios Casa Santa e Furna do Messias apresentam algumas características semelhantes, como: a utilização do adorno de cabeça tipo 4; e a interação cenográfica que é composta pelos dois antropomorfos presentes na cena (Quadro 9).

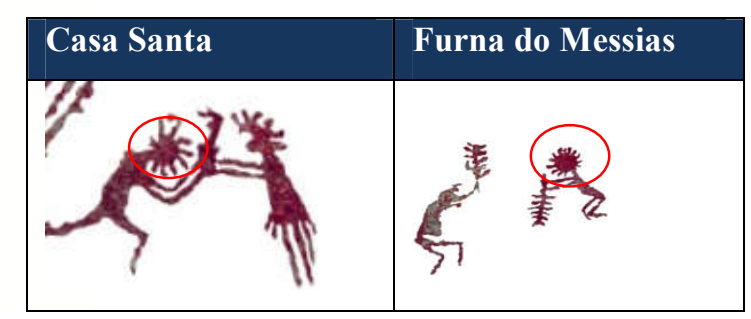

Quadro 9: Cenas herméticas similares com adornos de cabeça tipo 4.

As composições dos sítios Furna do Borrachinha, Serrote das Areias e Xique-Xique I apresentam, como característica, o uso do adorno tipo 8. Entretanto, os sítios Serrote das Areias e Xique-Xique I demonstram mais similaridades, como: os antropomorfos 
posicionados em fileiras; e a utilização do atributo cultural, caracterizado como uma arma (Quadro 10).

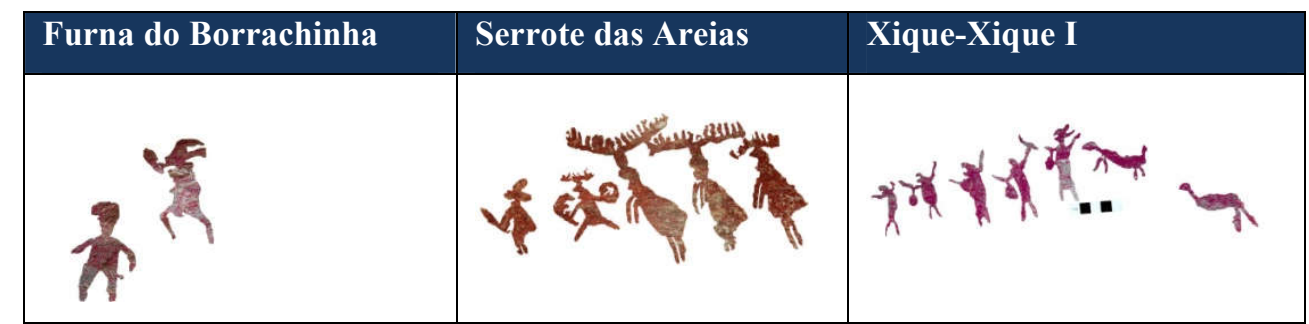

Quadro 10: Cenas herméticas similares com adornos de cabeça tipo 8.

As composições dos sítios Xique-Xique I e do Hélder apresentam duas características semelhantes, que são: o adorno de cabeça tipo 12; os antropomorfos em posição frontal, lado a lado e com membros superiores e inferiores flexionados (Quadro 11).

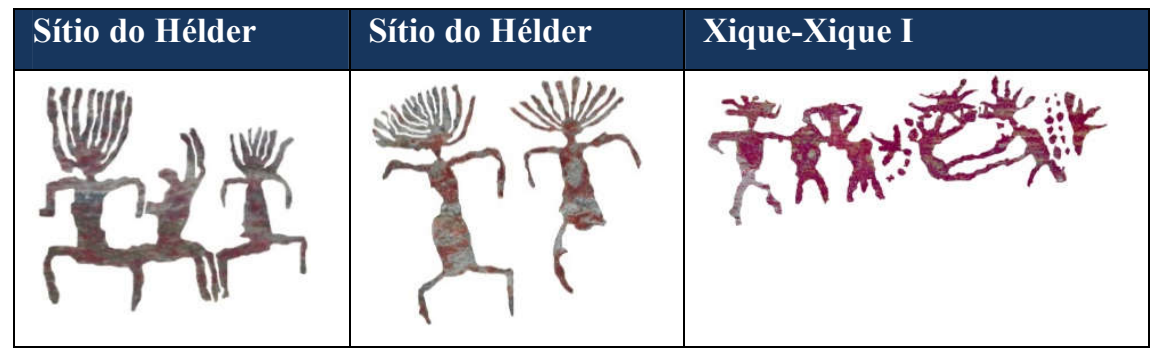

Quadro 11: Cenas herméticas similares com adornos de cabeça tipo 12.

Desse modo, foram avaliadas, continuamente, as demais formas de cenas expostas nos sítios arqueológicos estudados, como as cenas sexuais. A partir da identificação das cenas, foi constatado que esse tipo de expressão gráfica não é recorrente nos sítios arqueológicos estudados. Assim, foram avaliadas as cenas referentes aos sítios Furna do Messias e Xique-Xique I, sobre as similaridades e diferenças que comportam. 
Com isso, observou-se que ambos há a utilização do adorno tipo 5 e que os antropomorfos estão interagindo em dupla. Entretanto, o agenciamento dos antropomorfos difere nas composições cenográficas (Quadro 12).

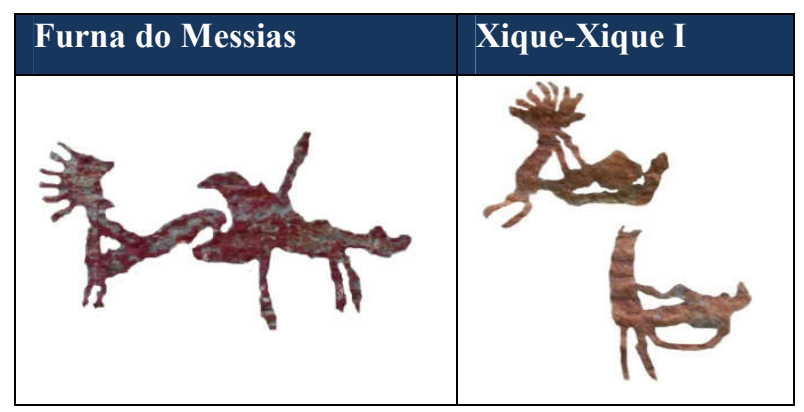

Quadro 12: Cenas sexuais que apresentam adornos de cabeça.

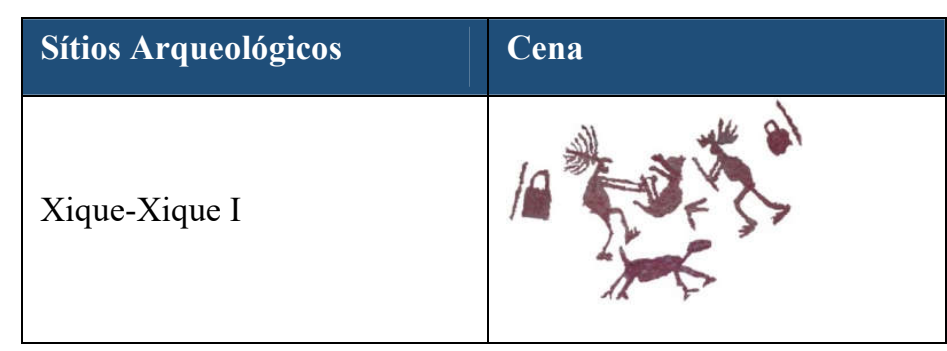

Quadro 13: Cena de caça que apresenta adorno de cabeça.

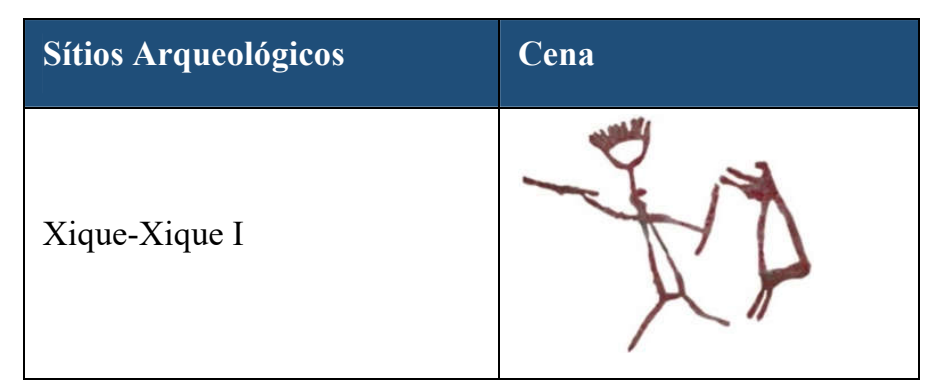

Quadro 14: Cena de violência que apresenta adorno de cabeça. 
A partir da identificação das cenas, foi constatado que as representações gráficas sobre as cenas de caça e violência (Quadros 13 e 14) não são recorrentes nos sítios arqueológicos estudados com a presença do adorno de cabeça. Em decorrência desse aspecto, não há como fazer comparações entre as similaridades e diferenças entre as composições cenográficas, como ocorreu com as cenas herméticas e sexuais.

$\mathrm{Na}$ dimensão técnica que constitui os estudos sobre os procedimentos técnicos da realização do registro rupestre, foi empregada a variável sobre o tratamento do suporte, com o objetivo de identificar um tratamento prévio na realização gráfica e se esse procedimento estaria ligado a alguma classificação tipológica dos atributos culturais ou das formas de apresentação gráfica.

$\mathrm{Na}$ investigação realizada sobre o suporte rochoso nos sítios arqueológicos, através da observação macroscópica, não foi identificado um tratamento prévio no suporte para a confecção das figuras estudadas, exibindo, geralmente, paredões irregulares.

\section{CONSIDERAÇÕES FINAIS}

Esta pesquisa abordou 9 sítios inseridos na bacia hidrográfica do Rio Carnaúba, que foram trabalhados em busca de ligações culturais demonstradas nas representações gráficas que apresentavam cenografias com adornos de cabeça nos antropomorfos.

O aporte das dimensões gráficas, o qual traduz, de forma analítica, o postulado em que a expressão gráfica de um grupo é resultado de um conjunto de normas, códigos e soluções técnicas, foi utilizado para discutir e responder à problemática inicial deste trabalho, que consistia em identificar a existência de correlações entre as composições cenográficas e os adornos de cabeça. 
Essas correlações de tipos de cenas e tipos de adornos podem apresentar normatizações gráficas que se traduzem em informações sobre grupos autores similares e divergentes. Representam, assim, comportamentos que possibilitam identificar padrões gráficos, considerando que as representações que foram exteriorizadas nos paredões rochosos participam de sistemas de organização social, mitos, entre outros, exibindo a materialidade de ideias, conceitos e abstração pertencentes aos grupos pré-históricos realizadores.

Dessa maneira, a investigação se deteve em identificar e depois segregar os tipos morfológicos dos adornos de cabeça nas cenas reconhecíveis, objetivando o reconhecimento das similaridades e diferenças nos padrões de apresentação gráfica.

Com isso, foram identificados, em 30 cenas, 17 tipos morfológicos de adornos de cabeça vinculados a 4 temáticas diferentes, sendo elas: hermética, sexual, violência e caça.

Através do alinhamento dos dados, notou-se que as cenas classificadas como herméticas são mais abrangentes nos sítios arqueológicos estudados, que detêm a maior quantidade de comparações entre as tipologias dos adornos de cabeça e as composições cenográficas nos sítios arqueológicos.

Embora as representações herméticas não expressem seu significado como cenas de caça, violência, entre outros, podemos identificar, a partir da constituição de seus traços, recorrências que podem caracterizar a existência de padrões gráficos. Assim, foram assinaladas as suas similaridades e diferenças e, com isso, a identificação de padrões em suas estruturas. 
As cenas com o tipo 2 do adorno de cabeça mostrou-se recorrente nos sítios Casa Santa, Furna da Desilusão, Furna do Messias, Xique-Xique II e Xique-Xique IV. Constata-se a presença de agenciamentos cenográficos semelhantes, que geralmente apresentam na composição cenográfica a presença de 2 ou 3 antropomorfos em posição frente a frente, exceto pelo sítio Furna do Messias, em que os antropomorfos aparecem sequencialmente. As cenas com o tipo 4 do adorno de cabeça apresentam similaridades em relação aos antropomorfos, que contêm a estrutura do corpo semelhante e estão acompanhados por um objeto de mão ou por um fitomorfo.

As cenas com o tipo 5 do adorno de cabeça apresentam similaridades entre os antropomorfos que trazem consigo o adorno de cabeça. Estão também associadas à presença de vestimenta.

As cenas com o tipo 8 do adorno de cabeça apresentam similaridades em relação aos antropomorfos dispostos de forma sequenciada e à presença de arma em sua constituição. As cenas com o tipo 12 do adorno de cabeça apresentam similaridades entre os antropomorfos, posicionados de forma frontal, lado a lado, e a disposição dos membros assemelha-se em relação à sua estrutura.

As cenas com o tipo 17 do adorno de cabeça apresentam similaridades entre os antropomorfos em suas disposições lado a lado, com a disposição corpórea semelhante. No que tange à investigação sobre as cenas que foram classificadas como sexuais, é possível observar a presença da utilização do adorno tipo 5 e o agenciamento entre dois antropomorfos.

Acerca das similaridades existentes em suas composições, não foram identificadas outras semelhanças gráficas para além do adorno de cabeça. 
As cenas de caça e violência que apresentam a utilização do adorno de cabeça do tipo 3 e 15, respectivamente, foram identificadas em apenas uma única composição cada. Assim, não houve as comparações entre suas similaridades e diferenças para a identificação de padrões gráficos sobre tal temática.

O estudo comparativo relacionado aos adornos de cabeça foi realizado em conjunto com os tipos de cena, entretanto é possível observar na análise que algumas tipologias não foram expostas, como é o caso dos tipos $1,6,7,9,10,11,13,16$ e 17; isso decorre da ausência da repetição desses tipos nas cenas estudadas, e com isso não pôde ser realizado o estudo comparativo das similaridades e diferenças expostas nas cenas.

Em conformidade ao que foi exposto em relação às cenas herméticas através da comparação das tipologias dos adornos de cabeça, foi permitido identificar padrões de apresentação gráfica, assinalada por meio do agenciamento dos elementos de cena e do uso de determinados atributos culturais, como o adorno de cabeça, a vestimenta e a arma.

Nessa perspectiva, com a identificação de alguns padrões gráficos pertinentes às cenas herméticas, foi avaliada a disposição espacial dos sítios perante as cenas analisadas.

Mediante esse parâmetro, relacionado com a análise das similaridades de apresentação gráfica em relação às tipologias dos adornos de cabeça, os sítios arqueológicos Casa Santa, Furna da Desilusão, Furna do Borrachinha, Furna do Messias, Xique-Xique I, Xique-Xique II, Serrote das Areias, Xique-Xique IV e Sítio do Hélder demonstraram similaridades gráficas a partir das composições herméticas e sexuais. 
Dessa forma, é confirmada a hipótese proposta na pesquisa de que há correlações entre as estruturas gráficas dos adornos de cabeça e as composições cenográficas, demonstrando, com isso, compartilhamento cultural entre os grupos realizadores das cenas estudadas.

Tendo em vista que, apesar das variabilidades demonstradas nas composições cenográficas em torno dos adornos de cabeça, os mesmos demonstram semelhanças nas estruturas dos parâmetros das dimensões do fenômeno gráfico, essas variabilidades podem ser associadas a identidades e alteridades refletidas nos conjuntos cenográficos por intermédio dos grupos pré-históricos.

Os registros rupestres estudados evidenciam comportamentos culturais dos grupos pretéritos, destacando preferências sobre a utilização do adorno de cabeça em relação aos momentos cenográficos. Por meio de um conjunto comparativo entre as similaridades e diferenças expostas nas cenas, foi possível identificar em quais circunstâncias os grupos culturais empregavam determinados adornos de cabeça, e com isso a pesquisa pôde obter dados acerca de algumas características culturais dos grupos realizadores da obra gráfica mediante a exibição de padrões de apresentação. Dessa forma, através da representação dos adornos de cabeça associados às cenas foi possível alcançar informações relativas à importância desses elementos para os grupos pré-históricos ressaltados mediante as expressões pictóricas expostas nos paredões rochosos - levando em consideração que os adornos de cabeça fazem parte de um processo cultural interno no qual assinalam as diferenças dos demais grupos, ressaltando sua identidade individual e grupal. 


\section{REFERÊNCIAS BIBLIOGRÁFICAS}

LEACH, E. Cultura y Comunicacion. La Logica de la Conexion de los Simbolos. Uma introducion al uso Del analisis estructuralistas em la antropologia social. Ed. Siglo Ventuno, 1978.

LEROI-GOURHAN, A. O gesto e a palavra 2 - memória e ritmos. Lisboa: Edições 70, 1965.

MARTIN, G. A Subtradição Seridó de Pintura Rupestre Pré-histórica do Brasil. Revista Clio - Arqueológica. Universidade Federal de Pernambuco-UFPE, Recife, 1989.

MARTIN, G. Fronteiras Estilísticas e Culturais na Arte Rupestre da Área Arqueológica do Seridó-RN. Revista Clio - Arqueológica. Universidade Federal de PernambucoUFPE, Recife, 2003.

MARTIN, G. et al. Levantamento na Área Arqueológica do Seridó - Rio Grande do Norte - Brasil: Nota Prévia. Revista Clio - Arqueológica. Universidade Federal de Pernambuco-UFPE, Recife, 2008.

PESSIS, A-M. Métodos de interpretação da arte rupestre. Revista Clio - Arqueológica. Universidade Federal de Pernambuco-UFPE, Recife, 1984.

PESSIS, A-M. Apresentação Gráfica e Apresentação Social na Tradição Nordeste de Pintura Rupestre do Brasil. Revista Clio - Arqueológica. Universidade Federal de Pernambuco-UFPE, Recife, 1989.

PESSIS, A-M. Identidade e classificação dos registros gráficos pré-históricos do Nordeste do Brasil. Revista Clio - Arqueológica, n. 8. Recife: UFPE, 1992.

PESSIS, A-M. Imagens da pré-história. FUMDHAM/PETROBRAS: São Paulo, 2003.

RIBEIRO, B. Suma Etnológica Brasileira III: arte índia. 3. ed. Petrópolis: Vozes, 1987.

SEEGER, A.; MATTA, R. da; CASTRO, E. B. A construção da pessoa nas sociedades indígenas brasileiras. Núcleo de Estudos e Assuntos Indígenas. Universidade Federal do Tocantins Campus de Porto, 1979. 
SANTOS JUNIOR, V. As técnicas de execução das gravuras rupestres do Rio Grande do Norte. FUMDHAmentos, v. VII, p. 516-528, 2008.

VIDAL, L.; MÜLLER, R. P. Pintura e adornos corporais. Darcy Ribeiro et alii (Eds.) Suma Etnológica Brasileira. Arte índia. Edição atualizada do Handbook of South American Indians, vol.3, Coord. Berta Ribeiro, Vozes, Petrópolis: 119-48. 1986. 